\title{
BENEFíCIO DE PRESTAÇÃO CONTINUADA, PROTEÇÃO SOCIAL E A REFORMA DA PREVIDÊNCIA
}

\section{ARTIGO ORIGINAL}

SANTOS, Caio Oliveira dos ${ }^{1}$

SANTOS, Caio Oliveira dos. Benefício de prestação continuada, proteção social e a reforma da previdência. Revista Científica Multidisciplinar Núcleo do Conhecimento. Ano 05, Ed. 05, Vol. 04, pp. 52-61. Maio de 2020. ISSN: 2448-0959, Link de acesso: https://www.nucleodoconhecimento.com.br/lei/beneficio-deprestacao

\section{RESUMO}

A reforma da previdência brasileira suscitou inúmeros debates, principalmente no campo da proteção social destinada aos idosos. O pressuposto de que o envelhecimento populacional suscitaria a necessidade de uma reforma previdenciária diante de um déficit da previdência se colocou em pauta durante os últimos anos no Brasil e no mundo. Diante disso, este artigo pretende demonstrar a importância que o Benefício de Prestação Continuada exerce na dignidade da pessoa idosa, razão pela qual deve ser afastada qualquer tentativa de mitigar esse direito. Para tanto optou-se pela adoção do método dedutivo por meio da reunião de premissas posteriormente confirmadas ou refutadas. No que tange ao procedimento, adotou-se o bibliográfico, que se dá pela reunião de livros, revistas, artigos científicos e jurisprudências que permitam a solução do problema proposto, qual seja identificar a importância que o

\footnotetext{
${ }^{1}$ Pós graduado Lato Sensu em Direito e Processo do Trabalho pela LFG em parceria com a Universidade Anhanguera(2016-2017) com Carga Horária de 426 horas. Especialista em Ciências Criminais com Carga Horária de 360 horas(2018-2019). Pós Graduando Lato Sensu em Direito Animal pela Uninter em parceria com a Escola da Magistratura Federal do Paraná (Esmafe). Possui graduação em Direito pelo Centro Universitário Jorge Amado (2015).
} 
BPC exerce na promoção da dignidade da pessoa idosa. Concluindo-se pela essencialidade do benefício de prestação continuada na garantia da satisfação de necessidades mínimas de sobrevivência para boa parte da população idosa.

Palavras-chave: Reforma da previdência, Previdência social, BPC, dignidade do idoso, pessoa idosa.

\section{INTRODUÇÃO}

A Reforma da Previdência brasileira, votada no ano de 2019, tinha como proposta inicial uma profunda modificação no Benefício de Prestação Continuada - BPC[2], que consiste em um benefício de natureza assistencial operada pela Previdência Social, e que se destina a idosos, pessoas com deficiência e doenças crônicas que não possuam meios de prover seu sustento[3]. O BPC responsabiliza anteriormente ao Estado, a própria família, considerando que a pessoa só é considerada elegível para o benefício caso a família não possua meios de prover o sustento deste sujeito.

Cabe salientar que, embora a modificação nos termos do BPC não tenha sido efetivada nesta primeira Reforma da Previdência, é de profunda importância que este assunto seja suscitado, isso porque o primeiro texto apresentado para esta reforma de 2019 previa a diminuição do valor do benefício[4], o que impactaria de profunda negativa e contundente a situação de idosos em situação de miserabilidade no país. Este artigo se propõe a realizar reflexões sobre o BPC especificamente no tocante à população idosa, visto que este público consiste no que mais cresce no Brasil, e serve como fundamento para a necessidade de uma reforma previdenciária de amplo espectro.

É relevante enfatizar que a própria proposta de reforma da previdência se pauta sobre a lógica segundo a qual o envelhecimento populacional resultaria em um déficit previdenciário. Ou seja, o fato de haver um número reduzido de pessoas em idade laboral e cada vez mais pessoas idosas seria uma questão a ser enfrentada[5]. O BPC, apesar de ser operado pela Previdência Social não se constitui como um benefício baseado na lógica contributiva, como é o caso da aposentaria, mas sim, é 
baseado na lógica da assistência social, onde todos aqueles que necessitam e se encaixam nos critérios pré-definidos pela legislação - a Lei Orgânica da Assistência Social (LOAS) devem acessar este benefício.

\section{PROTEÇÃO SOCIAL PARA IDOSOS E A REFORMA DA PREVIDÊNCIA}

Diante do processo de envelhecimento populacional fica evidente a necessidade de que o Estado dê respostas às demandas trazidas por esta população. $O$ fenômeno do envelhecimento populacional se mostra como um desafio no que se refere às políticas sociais, que precisam atender e responder à população em geral, e às demandas específicas dos idosos. No que concerne à área da saúde, por exemplo, diversas preocupações têm se colocado em pauta para o estabelecimento das bases para um envelhecimento saudável. Veras[6] aponta para a urgência de um desenvolvimento sistemático e eficaz que possibilite ações de promoção à saúde e prevenção de doenças, assim como modelos mais resolutivos e que sejam formulados e executados adequadamente considerando as peculiaridades do cuidado com os idosos.

A Constituição Brasileira de 88, conhecida também como a Constituição Cidadã é um marco no que se refere aos direitos sociais de forma geral, mas também quando é analisado o caso dos idosos de forma específica. Fica estabelecido na Constituição Federal de 88 que os idosos são cidadãos e precisam ter seus direitos garantidos[7]. O Artigo 230 define a responsabilidade pelo amparo das pessoas idosas como uma ação conjunta entre família, Estado e sociedade, e salienta a necessidade de que se assegure a participação dos idosos na sociedade e que seja realizada a defesa de sua dignidade, bem-estar e o direito à vida. Esta garantia constitucional impulsiona e possibilita a criação da Política Nacional do Idoso (PNI) no ano de 1994, um marco importantíssimo no que se refere ao reconhecimento dos direitos da população idosa no Brasil.

A PNI é um considerável avanço e se configura enquanto um documento norteador para a criação e implementação de políticas sociais públicas voltadas para os idosos. É através do PNI que se define a idade de 60 anos para designar a pessoa idosa, e 
que é criado o Conselho Nacional do Idoso. Conforme aponta Aguiaro[8] também é de suma importância mencionar a promulgação, no ano de 1999, da Política Nacional de Saúde do Idoso (PNSI), que buscou garantir atenção integral à saúde da população idosa, estando em conformidade com a Lei Orgânica da Saúde 8.080/90 e também com a Lei 8142/94 que regulamenta o Sistema Único de Saúde (SUS).

No ano de 2003 foi promulgado o mais recente marco no que se refere aos direitos das pessoas idosas, através da Lei 10.741: o Estatuto do Idoso[9]. O Estatuto do Idoso tem como base fundamental garantir e embasar os direitos constitucionais da pessoa idosa, compreendida como aquelas que possuem idade igual ou superior a 60 anos. Logo no primeiro artigo do Estatuto do Idoso se reafirma o compromisso e dever do Estado de regular e fomentar os diretos das pessoas idosas. O princípio da dignidade humana constitucional se mostra como o alicerce e o objetivo do Estatuto. Aguiaro[10] argumenta que o Estatuto do Idoso foi criado como uma forma de sinalizar que a população idosa estava "esquecida nas páginas da Constituição", uma vez que os direitos sociais específicos das pessoas acima de 60 anos encontram-se frequentemente negligenciados em diversos âmbitos, seja o familiar ou do Estado.

O Artigo 2 do Estatuto do Idoso reafirma a lógica da proteção integral dos idosos, assim como seus direitos fundamentais enquanto cidadãos, ratificando o artigo 5 da Constituição Federal, que trata de forma geral, sobre os direitos e as garantias fundamentais de todos os cidadãos brasileiros. No entanto, conforme aponta Frange[11] o Estatuto ultrapassa as normas constitucionais, reconhecendo os direitos específicos das pessoas idosas.

Outro avanço importante no que diz respeito às garantias trazidas pelo Estatuto do Idoso está disposto no artigo 33, que determina que a assistência social será efetuada de forma articulada, conforme os princípios e diretrizes previstos na Lei Orgânica da Assistência Social - LOAS, na Política Nacional do Idoso - PNI e no Sistema Único de Saúde - SUS. É importante destacar, no entanto, que a política de Assistência Social, de acordo com a análise de Sposati[12] tem enfrentado desafios para se consolidar enquanto direito social desde a Constituição Federal de 1988. É uma política ainda encarada com forte estigma e desconfiança, e implementada atualmente 
a partir de alta seletividade e focalização. Dito de outra forma, a seletividade está colocada como uma forma de conceder os benefícios de assistência social somente aos usuários em condição de miserabilidade.

Complementando no art. 34:

Aos idosos, a partir de 65 (sessenta e cinco) anos, que não possuam meios para prover sua subsistência, nem de tê-la provida por sua família, é assegurado o benefício mensal de 1 (um) salário-mínimo, nos termos da Lei Orgânica da Assistência Social - Loas.[13]

No artigo transcrito acima encontra-se uma das garantias hoje fundamentais e imprescindíveis para os idosos que se encontram em condição de vulnerabilidade social, e sem condições financeiras de garantir o seu sustento. É relevante observar, no entanto, que antes de responsabilizar o Estado, há a responsabilização da família. Somente em caso de não haver possibilidade de manter sua subsistência e de também não tê-lo provido por sua família, é que então o idoso possui o direito de requerer o Benefício de Prestação Continuada (BPC), que corresponde a um salário mínimo, e constitui um benefício de assistência social, operacionalizado pelo Instituto Nacional de Seguridade Social (INSS).

\section{BENEFÍCIO DE PRESTAÇÃO CONTINUADA (BPC)}

O BPC conforme mencionado anteriormente se configura enquanto um benefício de assistência social previsto pela Lei Orgânica da Assistência Social (LOAS) e que pode ser acessado por idosos acima de 65 anos e pessoas com deficiência que comprovem não ter condições de prover suas necessidades básicas e nem de tê-las providas por seu núcleo familiar. Para acessar o benefício é necessário ser brasileiro nato ou naturalizado ou de nacionalidade portuguesa[14]. De acordo com o Instituto Nacional de Seguridade Social, que atua como operacionalizador deste benefício, compreendese como grupo familiar aqueles que vivem sob o mesmo teto. Para ter direito ao BPC, o usuário e sua família devem necessariamente estar inscritos no Cadastro de Pessoa Física (CPF) e apresentar os seguintes documentos: Certidão de nascimento; 
Certidão de casamento; Certidão de reservista; Carteira de identidade; ou Carteira de Trabalho e Previdência Social (CTPS)[15].

O BPC faz parte da Proteção Social Básica do Sistema único de Assistência Social (SUAS), sendo assim, para acessar este benefício o usuário não necessita ter contribuído com a Previdência Social. O BPC não pode ser recebido por quem já possui outros benefícios no âmbito da Seguridade Social ou mesmo de outro regime, com exceção para "benefícios da assistência médica, pensões especiais de natureza indenizatória e a remuneração advinda de contrato de aprendizagem"[16].

A Agência da Previdência Social (APS) é responsável pela operacionalização do BPC. Desde o ano de 2016, por conta da publicação do Decreto no 8.805/2016, é necessário que o cidadão realize o Cadastro Único para realizar o requerimento do benefício. Desta forma, o usuário obrigatoriamente deve procurar o Centro de Referência de Assistência Social (CRAS)[17] para realizar o Cadastro Único para assim poder requerer o benefício e acessá-lo caso seja comprovado que possui este direito, atendendo aos requisitos necessários.

O Cadastro Único se consolidou ao longo dos últimos anos como uma importante ferramenta no que concerne à identificação de famílias de baixa renda, permitindo que o poder público tenha mais subsídios e informações sobre a realidade econômica das pessoas que necessitam da Assistência Social[18]. O Cadastro Único reúne informações sobre as residências dos usuários, assim como dados de identificação de cada pessoa que compõe o grupo familiar, situação de trabalho e renda, dentre outras.

É relevante destacar que, de acordo com as diretrizes do Estatuto do Idoso, Lei no 10.741/2003, o BPC de uma pessoa idosa não é considerado para o cálculo da renda mensal para a possível concessão do BPC para outra pessoa idosa que seja da mesma família. Considerando esta mesma lógica, benefícios como o Bolsa Família, que constitui um programa de transferência de renda, também não é considerado para o cálculo da renda familiar para fins de recebimento e concessão do BPC[19]. 
Considera-se renda mensal bruta familiar a soma dos rendimentos brutos auferidos mensalmente pelos membros da família composta por a) salários; b) proventos; c) pensões; d) pensões alimentícias; e) benefícios de previdência pública ou privada; f) comissões; g) pró-labore; h) outros rendimentos do trabalho não assalariado; i) rendimentos do mercado informal ou autônomo; j) rendimentos auferidos do patrimônio; e k) Renda Mensal Vitalícia e Benefício de Prestação Continuada, dentre outros, ressalvado o caso de concessão do benefício a outro idoso da mesma família.[20]

\section{PERSPECTIVAS FUTURAS}

Atualmente circulam propostas de modificações nos parâmetros e diretrizes do BPC. A PEC no 287/2016 reúne algumas propostas para tornar o BPC menos oneroso para o Estado, dentre elas, há a proposta de elevação da idade mínima de 65 para 70 anos e também a desvinculação do valor do benefício ao salário mínimo, possibilitando assim sua redução em um futuro próximo. É relevante salienta que estas propostas ocorrem em um contexto de contrarreforma do Estado, onde há um progressivo desmonte das políticas sociais a partir do argumento de que haveria uma crise fiscal que justificaria a necessidade de redução de custos, que impactam, sobretudo, a área social[21]. Compreende-se assim que não se trata de uma proposta isolada e que deve ser analisada a partir do contexto econômico social contemporâneo neoliberal.

De acordo com pesquisadores há argumentos sustentados pelos governos que associam o BPC voltado para as pessoas idosas à um desestímulo no que se refere à contribuição previdenciária[22]. De acordo com esta ideia, as pessoas menos qualificadas e que recebem remunerações próximas ao valor do salário mínimo, deixariam de contribuir para a previdência justamente porque haveria a possibilidade de alcançando a idade mínima receber o BPC, que possui o mesmo teto das aposentadorias de valor mais baixo. Os autores Jaccoud, Mesquita e Paiva[23], no entanto, assinalam que existem diversas diferenças entre o BPC e as aposentadorias, e que, portanto, este argumento parece estar equivocado. 
Há ainda a questão que se refere à diminuição da cobertura previdenciária ligada à uma redução na oferta de empregos formais no país. De acordo com a análise dos autores anteriormente citados este é um dos fatores que contribui para que ganhem força as propostas de modificações nos parâmetros do BPC, uma vez que já se prevê um aumento de pessoas idosas, que não conseguirão se aposentar e precisarão acessar a assistência social.

\section{CONSIDERAÇÕES FINAIS}

O fenômeno do envelhecimento populacional no Brasil tem colocado novos questionamentos e desafios para o campo das políticas sociais e públicos no país. Para a Saúde estão colocadas questões como por exemplo o crescimento no número de pessoas idosas com doenças crônicas que exigem tratamentos custoso e de longo prazo. Para a Assistência Social se coloca a realidade de um aumento no número de idosos que necessitam acessar benefícios assistenciais. Assim, estudiosos e pesquisadores tem apontado para a necessidade de formulação e adequação das políticas sociais à nova realidade social colocada por uma população idosa crescente. Por outro lado, a contrarreforma e o desmonte da proteção social também se configuram enquanto uma realidade a ser enfrentada. A Assistência Social, que historicamente teve imensas dificuldades para se consolidar como um direito social e se afastar da lógica caritativa e assistencialista, na contemporaneidade se coloca como um desafio à parte. A promulgação do Estatuto do idoso é um marco no que confere ao reconhecimento por parte do Estado da necessidade de lidar com esta questão através de políticas e serviços especificamente voltados para esta parcela da população, que requer um olhar atento.

O Benefício de Prestação Continuada é um benefício fundamental do âmbito da Assistência Social para idosos em situação de vulnerabilidade social e econômica. A partir das reflexões aqui colocadas evidencia-se a necessidade de discutir e fomentar os debates em torno deste benefício. A lógica atual, de redução de custos sociais, tende a comprometer a proteção social para os idosos, considerando inclusive a diminuição drástica do emprego formal, e consequentemente do número de pessoas que contribui para a Previdência Social e terão acesso ao benefício da aposentadoria. 
Torna-se fundamental a elaboração de estratégias para a consolidação da Assistência Social como direito social, conforme define a Constituição Federal de 1988, para que se possa realizar avanços significativos neste campo.

\section{REFERÊNCIAS}

AGUIARO, Felipe Fragoso. 0 idoso como cidadão: entendendo o abandono familiar da pessoa idosa. Dissertação de Mestrado, Universidade Federal Fluminense, 2016.

BEHRING, E. R.; BOSCHETTI, I. Política Social: Fundamentos e História. São Paulo: Cortez, 2006.

BRASIL. Lei Federal no 10.741, de 01 de Outubro de 2003. Estatuto do Idoso. Disponível em: <http://www.planalto.gov.br/ccivil_03/leis/2003/l10.741.htm> acesso em: 12 mai. 2020.

BRASIL. Lei Federal № 8.742, de 7 de Dezembro de 1993. Lei Orgânica da Assistência Social. Disponível em: <http://www.planalto.gov.br/ccivil_03/Leis/L8742compilado.htm> acesso em: 12 mai. 2020.

BRASIL. Lei no 8.742 de 7 de dezembro de 1993 . Disponível em:<http://www.planalto.gov.br/ccivil_03/leis//8742.htm> acesso em: 12 mai. 2020.

CÂMARA DOS DEPUTADOS. Proposta de emenda à Constituição no 6/2019. Disponível em: $<$ https://www.camara.leg.br/proposicoesWeb/fichadetramitacao?idProposicao=21924 59> acesso em: 12 mai. 2020.

CAMARANO, A. A. Envelhecimento da população brasileira: continuação de uma tendência. 2011. Disponível em: <http://www.coletiva.org/site/index.phpopt ion $=$ com_k2\&view $=i$ tem \&layout $=i$ tem $\&$ id $=58 \& \mid t e m i d=76 \& i d r e v=8>$. Acessado $23 \mathrm{de}$ outubro de 2018. 
FRANGE, Paulo. Estatuto dos Idosos comentado. Uberaba, 2004.

IBGE. Censo demográfico 2010: famílias e domićlios (resultados da amostra). Rio de Janeiro, 2011. Disponível em: <http://censo2010.ibge.gov.br>. Acesso em: 20 ago. 2013.

JACCOUD, L. B.; MESQUITA, A. C. S.; PAIVA, A. B. O BPC: dos avanços aos riscos da reforma previdenciária. Ciênc. saúde colet. 22 (11) Nov 2017. Disponível em: https://www.scielosp.org/article/csc/2017.v22n11/3499-3504/pt/. Acesso em: 25/11/2018.

MDS. Ministério do Desenvolvimento Social. 0 benefício de prestação continuada: guia para técnicos e gestores da assistência social. Secretaria Nacional de Assistência Social (SNAS), Brasília, 2018. Disponível em: http://www.mds.gov.br/webarquivos/publicacao/assistencia_social/Guia/Guia_BPC_2 018.pdf. Acesso em: 28/11/2018.

SPOSATI, Aldaíza. Assistência social: de ação individual a direito social. Revista Brasileira de Direito Constitucional - RBDC n. 10 - jul./dez. 2007.

VERAS, Renato. Novos desafios para o jovem país envelhecido. In: Corpo, envelhecimento e felicidade, Miriam Goldenberg (Org.), 2011.

\section{APÊNDICE - REFERÊNCIAS DE NOTA DE RODAPÉ}

2. CÂMARA DOS DEPUTADOS. Proposta de emenda à Constituição ํo 6/2019. Disponível em: $<$ https://www.camara.leg.br/proposicoesWeb/fichadetramitacao?idProposicao=21924 59> acesso em: 12 mai. 2020.

3. BRASIL. Lei $\mathrm{n}^{0} 8.742$ de 7 de dezembro de 1993 . Disponível em:<http://www.planalto.gov.br/ccivil_03/leis//8742.htm> acesso em: 12 mai. 2020.

4. Nota 1. 
5. PERA, Ana Carolina lanovali. Reforma da Previdência: entenda como o envelhecimento da população afeta os cofres públicos. Publicado em: 27 de jan. 2017. Disponível em: <https://www.migalhas.com.br/depeso/252650/reforma-daprevidencia-entenda-como-o-envelhecimento-da-populacao-afeta-os-cofrespublicos> acesso em: 12 mai. 2020.

6. VERAS, Renato. Novos desafios para o jovem país envelhecido. In: Corpo, envelhecimento e felicidade, Miriam Goldenberg (Org.), 2011.

7. BRASIL. Constituição da República Federativa do Brasil. Disponível em: http://www.planalto.gov.br/ccivil_03/Constituicao/ConstituicaoCompilado.htm. Acesso em: 12 mai. 2020.

8. AGUIARO, Felipe Fragoso. O idoso como cidadão: entendendo o abandono familiar da pessoa idosa. Dissertação de Mestrado, Universidade Federal Fluminense, 2016.

9. BRASIL. Estatuto do Idoso. Lei Federal nํ 10.741, de 01 de Outubro de 2003. Disponível em: <http://www.planalto.gov.br/ccivil_03/leis/2003/l10.741.htm> acesso em: 12 mai. 2020.

10. Nota 7 .

11. FRANGE, Paulo. Estatuto dos Idosos comentado. Uberaba, 2004.

12. SPOSATI, Aldaíza. Assistência social: de ação individual a direito social. Revista Brasileira de Direito Constitucional - RBDC n. 10 - jul./dez. 2007.

13. BRASIL. Lei Federal № 8.742, de 7 de Dezembro de 1993. Lei Orgânica da Assistência Social. Disponível em: <http://www.planalto.gov.br/ccivil_03/Leis/L8742compilado.htm> acesso em: 12 mai. 2020.

14. MDS, Ministério do Desenvolvimento Social. O benefício de prestação continuada: guia para técnicos e gestores da assistência social. Secretaria Nacional de Assistência Social (SNAS),

Brasília, 2018

Disponível

em: 
$<$ http://www.mds.gov.br/webarquivos/publicacao/assistencia_social/Guia/Guia_BPC_ 2018.pdf> Acesso em: 28/11/2018.

15. Idem.

16. Idem.

17. "O CRAS é o órgão gestor local da Política de Assistência Social e tem como atribuição orientar a pessoa idosa e a pessoa com deficiência, assim como seus familiares, sobre o acesso ao benefício, bem como assegurar aos requerentes e/ou beneficiários do BPC e suas famílias o acesso aos serviços da rede socioassistencial e de outras políticas públicas, conforme suas necessidades, considerando a situação de vulnerabilidade e risco social em que se encontram" (MDS, 2018, p. 13).

18. Nota 13.

19. Nota 13.

20. Nota 13.

21. BEHRING, E. R.; BOSCHETTI, I. Política Social: Fundamentos e História. São Paulo: Cortez, 2006.

22. JACCOUD, L. B.; MESQUITA, A. C. S.; PAIVA, A. B. O BPC: dos avanços aos riscos da reforma previdenciária. Ciênc. saúde colet. 22 (11) Nov 2017. Disponível em: https://www.scielosp.org/article/csc/2017.v22n11/3499-3504/pt/. Acesso em: 25/11/2018.

23. Idem.

Enviado: Abril, 2020.

Aprovado: Maio, 2020. 